Article

\title{
Synthesis of Ni-Doped ZnO Nanorod Arrays by Chemical Bath Deposition and Their Application to Nanogenerators
}

\author{
Yen-Lin Chu ${ }^{1} \mathbb{D}$, Sheng-Joue Young ${ }^{2, *} \mathbb{D}$, Liang-Wen Ji ${ }^{1, *}$, Tung-Te Chu ${ }^{3}$ and Po-Hao Chen ${ }^{1}$ \\ 1 Department of Electro-Optical Engineering, Institute of Electro-Optical and Materials Science, \\ National Formosa University, Yunlin 632, Taiwan; 10576123@gm.nfu.edu.tw (Y.-L.C.); \\ juerpoker@yahoo.com.tw (P.-H.C.) \\ 2 Department of Electronic Engineering, National Formosa University, Yunlin 632, Taiwan \\ 3 Department of Mechanical Automation Engineering, Kao Yuan University, Kaohsiung 821, Taiwan; \\ t30039@cc.kyu.edu.tw \\ * Correspondence: shengjoueyoung@gmail.com (S.-J.Y.); lwji@nfu.edu.tw (L.-W.J.)
}

Received: 27 April 2020; Accepted: 22 May 2020; Published: 29 May 2020

\begin{abstract}
Nanogenerators (NGs) based on Ni-doped ZnO (NZO) nanorod (NR) arrays were fabricated and explored in this study. The $\mathrm{ZnO}$ films were grown on indium tin oxide (ITO) glass substrates, and the NZO NRs were prepared by the chemical bath deposition (CBD) method. The samples were investigated via field-emission scanning electron microscopy (FE-SEM) and X-ray diffraction (XRD) spectral analysis. The results showed that the growth of NRs presented high-density single crystalline structures and were preferentially oriented in the c-axis direction. The optical characteristics of the NZO NRs were also measured by photoluminescence (PL) spectra. All samples exhibited two different emissions, including ultraviolet (UV) and green emissions. ITO etching paste was used to define patterns, and an electrode of Au film was evaporated onto the ITO glass substrates by the electron beam evaporation technique to assemble the NG device. In summary, $\mathrm{ZnO} \mathrm{NRs}$ with $\mathrm{Ni}$ dopant $(5 \mathrm{mM})$ showed significantly excellent performance in NGs. The optimal measured voltage, current, and power for the fabricated NGs were $0.07 \mathrm{~V}, 10.5 \mu \mathrm{A}$, and $735 \mathrm{nW}$, respectively.
\end{abstract}

Keywords: $\mathrm{ZnO}$; nanogenerator; nanorods; $\mathrm{Ni}$; $\mathrm{CBD}$ method

\section{Introduction}

The human demand for energy has reached an unprecedented level in recent decades because of the expansion of the earth's population and the industrialization of developing countries. At the same time, primary energy (PE) is also being exhausted daily ( $\mathrm{PE}$ is an energy form found in nature that has not been subjected to any human engineered conversion process). Thus, this constitutes a very important reason to find novel renewable and ecologically pure alternative energy sources. Researchers are concerned with the limited electric equipment and power supply system used for collecting waste energy in our living surroundings [1,2]. At present, nanogenerators (NGs) are designed for transforming mechanical energy into electric energy [3,4]. These NGs are combined with one-dimensional (1-D) nanostructures for application in portable or wearable devices to collect energy for the supply of electric power in the future. In 1-D ZnO NG devices, NGs can be divided into three types, namely, piezoelectric (PZ), triboelectric, and pyroelectric applications [5-7]. NGs can also be applied in surface acoustic wave (SAW) devices [8]. Dopant and flexible substrates can improve the output power efficiency of $\mathrm{ZnO}$ piezoelectricity and enhance the optical and electric characteristics of $\mathrm{ZnO}$ [9].

Metal oxide semiconductors (MOSs) have been used interestingly in many research fields because of their outstanding properties, such as a low cost, excellent controllability, and good integration 
with the microfabrication of silicon. Among all, $\mathrm{ZnO}$ is an n-type semiconductor and a II-VI group compound with a direct bandgap energy band structure; its energy gap is $3.37 \mathrm{eV}$, and it has a large exciton binding energy $(60 \mathrm{meV})$ [10]. Moreover, the bandgap of $\mathrm{ZnO}$ is larger than other semiconductor materials, such as $\mathrm{ZnS}(40 \mathrm{meV}), \mathrm{ZnSe}(20 \mathrm{meV})$, and $\mathrm{GaN}(25 \mathrm{meV})$ [11-13]. ZnO-based low-dimensional materials exhibit low resistivity and high transparency in the visible-light area. Meanwhile, $\mathrm{ZnO}$ material is a wurtzite hexagonal structure with lattice constants of a $=3.24-3.26 \AA$ and $\mathrm{c}=5.13-5.43 \AA$ at room temperature. Among the known 1-D nanomaterials, ZnO material has some benefits: (1) it shows both semiconducting and PZ properties that can form the basis for electromechanically coupled sensors and transducers; (2) $\mathrm{ZnO}$ is a relatively biocompatible property, which can be employed in biomedical applications with little toxicity; (3) $\mathrm{ZnO}$ material reveals the most diverse and abundant morphologies of nanostructures known so far. These properties also demonstrate distinctive electric and optical characteristics. Hence, $\mathrm{ZnO}$ materials are promising for modern day applications. In recent years, $\mathrm{ZnO}$ materials have been used in optoelectronic devices, such as pH sensors, photodetectors (PDs), NGs, light-emitting diodes (LEDs), gas sensors, and field-emission displays [14-19]. The developments of various nanostructure techniques have resulted in the creation of $\mathrm{ZnO}$ structures. For instance, thermal evaporation, pulsed laser deposition (PLD), metal organic chemical vapor deposition (MOCVD), and chemical bath deposition (CBD) have been successfully used in producing highly oriented $\mathrm{ZnO}$ structures [20-23]. CBD is a simple, inexpensive, and low-temperature method for wet chemistry and has become a promising mechanism for the large-scale production of nanostructures. $\mathrm{CBD}$ was used to prepare $\mathrm{ZnO}$ nanostructures in our experiments owing to its above-mentioned advantages.

NGs have been developed by using ZnO NRs or ZnO nanowire (NW) arrays. Wang et al. (2006) fabricated $\mathrm{ZnO} \mathrm{NW}$ arrays on $\mathrm{Al}_{2} \mathrm{O}_{3}$ substrates by the vapor-liquid-solid (VLS) method with $\mathrm{Au}$ nanoparticles as the catalyst. Subsequently, the PZ characteristics of NWs were measured and studied by atomic force microscopy (AFM) tip [24]. Wang et al. (2007) packaged ZnO NWs and applied an ultrasonic oscillating source to drive $\mathrm{ZnO} N W$ array devices and produce electric power [25]. In this paper, Ni was used as a dopant. Ni has many chemical and physical properties, such as chemical stability, corrosion resistance, and good electrical and thermal conductivity. The ionic radii of $\mathrm{Ni}^{2+}(0.069 \mathrm{~nm})$ are similar to that of $\mathrm{Zn}^{2+}(0.074 \mathrm{~nm})$, and the valence of $\mathrm{Zn}^{2+}$ is the same as that of $\mathrm{Ni}^{2+}$. These phenomena lead to the charge separation and transport of $\mathrm{ZnO}$ structures, thereby enhancing the electrical and optical efficiency of devices [26]. ZnO structures with $\mathrm{Ni}$ content can improve the property of materials and the sensitivity of NGs. This study was aimed at further improving the understanding of the characteristics of $\mathrm{Ni}^{2+}$ in nanostructures, and applying it to photoelectric devices. In this work, NGs based on pure $\mathrm{ZnO}$ and $\mathrm{Ni}$-doped $\mathrm{ZnO}(\mathrm{NZO})$ nanorods (NRs) were prepared, and the NGs were driven by an ultrasonic wave to measure their voltage, current, and power. The results reveal that NZO nanostructures can enhance the output efficiency of voltage, current, and power of NGs.

\section{Experimental}

The NGs based on NZO ZnO NR arrays were fabricated in two steps. (1) During deposition, a $\mathrm{ZnO}$ target with a 3-inch diameter and purity of $99.99 \%$ was used. A $100 \mathrm{~nm}$ layer of $\mathrm{ZnO}$ film was grown on $1 \times 1.5 \mathrm{~cm}^{2}$ indium tin oxide (ITO) glass substrates via a radio frequency (RF) magnetron sputtering technique (vacuum of $\left.5 \times 10^{-6} \mathrm{Torr}\right)$. The $\mathrm{RF}$ power and gas mixing ratio $\left(\mathrm{Ar} / \mathrm{O}_{2}\right)$ were $100 \mathrm{~W}$ and 10/1, respectively. Subsequently, the samples were dipped in 1:2 proportion of $0.015 \mathrm{M}$ zinc acetate dihydrate $\left(\mathrm{Zn}\left[\mathrm{CH}_{3} \mathrm{COO}_{2} \bullet 2 \mathrm{H}_{2} \mathrm{O}, 99.99 \%\right)\right.$ and $0.03 \mathrm{M}$ hexamethylenetetramine $\left(\mathrm{C}_{6} \mathrm{H}_{12} \mathrm{~N}_{4}\right.$, HMTA) with different concentrations of $\mathrm{Ni}(\mathrm{II})$ acetate $\left.\left(\mathrm{Ni}_{\mathrm{C}} \mathrm{CH}_{3} \mathrm{COO}\right]_{2}, 99.8 \%\right)$ solution $(0$ and $5 \mathrm{mM})$; CBD was used to grow NZO NRs in a $95^{\circ} \mathrm{C}$ oven for $3 \mathrm{~h}$. The Ni dopant was supplied from $\mathrm{Ni}(\mathrm{II})$ acetate, and the reaction formulas of $\mathrm{ZnO}$ are as follows [27]:

$$
\mathrm{C}_{6} \mathrm{H}_{12} \mathrm{~N}_{4}+6 \mathrm{H}_{2} \mathrm{O} \rightarrow 6 \mathrm{HCHO}+4 \mathrm{NH}_{3}
$$




$$
\begin{aligned}
\mathrm{NH}_{3}+\mathrm{H}_{2} \mathrm{O} \rightarrow \mathrm{NH}_{4}^{+}+\mathrm{OH}^{-} \\
\mathrm{Zn}\left(\mathrm{CH}_{3} \mathrm{COO}_{2}\right)_{1-\mathrm{x}}\left(\mathrm{NiCH}_{3} \mathrm{COO}_{2}\right)_{\mathrm{x}} \rightarrow\left(\mathrm{Zn}_{1-\mathrm{x}} \mathrm{Ni}_{\mathrm{x}}\right)^{2+}+2 \mathrm{CH}_{3} \mathrm{COO}^{-} \\
\left(\mathrm{Zn}_{1-\mathrm{x}} \mathrm{Ni}_{\mathrm{x}}\right)^{2+}+2 \mathrm{OH}^{-} \rightarrow\left(\mathrm{Zn}_{1-\mathrm{x}} \mathrm{Ni}_{\mathrm{x}}\right)(\mathrm{OH})_{2} \\
\left(\mathrm{Zn}_{1-\mathrm{x}} \mathrm{Ni}_{\mathrm{x}}\right)(\mathrm{OH})_{2} \rightarrow \mathrm{Ni} \mathrm{ZnO}+\mathrm{H}_{2} \mathrm{O}
\end{aligned}
$$

After the completion of the reaction, the samples were rinsed with deionized (DI) water and dried in an oven for $5 \mathrm{~min}$ at $100{ }^{\circ} \mathrm{C}$. Then, the surface morphology of the NZO NRs was characterized with field-emission scanning electron microscopy (FE-SEM, JEOL JSM-6700F) and high-resolution transmission electron microscopy (HR-TEM, JEOL JEM-3010). The elemental, crystallographic, and optical material properties of NZO NRs were analyzed via energy dispersive X-ray (EDX) spectrometry, X-ray diffraction (XRD) spectral analysis (MO3XHF22 MAC-Science), and photoluminescence (PL) spectrometry (Labram HR), respectively.

(2) The patterns were defined on the ITO glass substrates, and ITO etching paste was used as etchant for etching in an oven at $170{ }^{\circ} \mathrm{C}$ for $5 \mathrm{~min}$. After this, the samples were cooled down for $10 \mathrm{~min}$ under room temperature and immersed in acetone, isopropyl alcohol, and DI water for individual cleaning for $1 \mathrm{~min}$. A $100 \mathrm{~nm}$ Au layer was subsequently evaporated onto the surface as electrode by using electron beam evaporation technique. Lastly, the NZO NR arrays and electrode were combined to form NG devices and then placed in an ultrasonic oscillator machine with a water chamber. An ultrasonic wave was applied to drive the NG devices. A precision digital meter (Keithly 2400) was connected by copper tape to measure the average current, voltage, and power, as shown in Figure 1a-b. This experimental process was similar to that previously reported by Chen et al. [28].

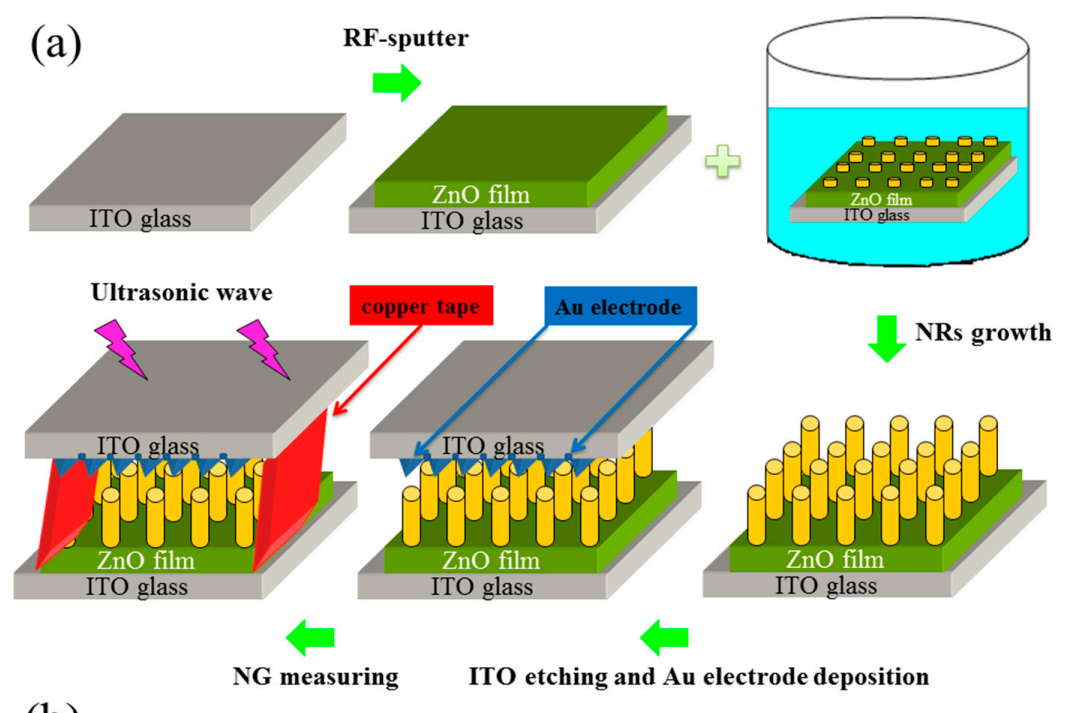

(b)

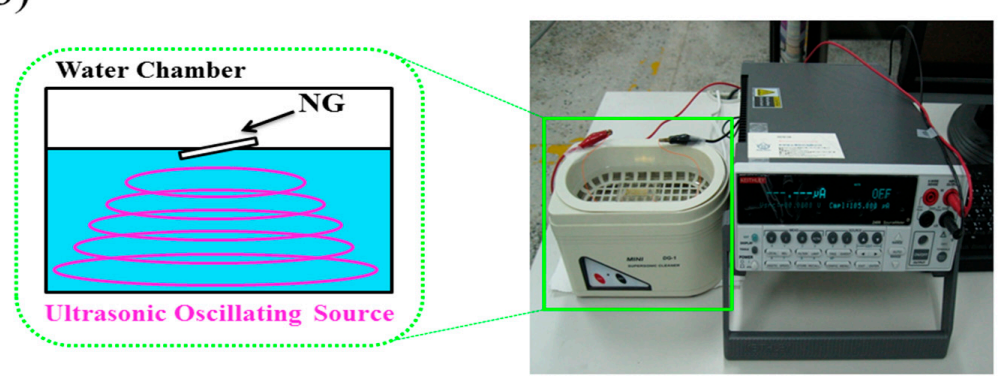

Figure 1. (a) Fabrication process of nanogenerators (NGs) based on Ni-doped ZnO (NZO) nanorod (NR) arrays; (b) Schematic of the sensing setup. 


\section{Results and Discussion}

To prepare pure $\mathrm{ZnO}$ and NZO NR structures, all the regents were analytically uncontaminated and used without further purification. The NR structures were grown on $\mathrm{ZnO}$ films for $3 \mathrm{~h}$ at $95^{\circ} \mathrm{C}$ by CBD. Figure 2 shows the nanostructural analysis of the as-grown pure $\mathrm{ZnO}$ and NZO NRs obtained by FE-SEM. It can be observed that pure ZnO NRs were vertically grown on the substrate. The height of NRs was $1.76 \mu \mathrm{m}$. With a Ni dopant of $5 \mathrm{mM}$, the cross-sectional surface of ZnO NRs strongly increased, and the length of NRs slightly decreased. The height of NRs was $1.72 \mu \mathrm{m}$. The images show that the surface of $\mathrm{ZnO}$ NRs changed and became dense because of the Ni dopant. The growth mechanism can be attributed to the higher bonding energy of $\mathrm{Ni}-\mathrm{O}$ than $\mathrm{Zn}-\mathrm{O}$. The surface energy between the polar and nonpolar surfaces differed, thereby enhancing the lateral growth and inhibiting the vertical one. This growth process was similar to that previously reported by Kim et al. and Dong et al. [29,30].

With regard to the phase and lattice constant identification, the structural characteristics were determined via XRD analysis, including $\mathrm{Cu} \mathrm{K} \alpha-1$ radiation and $\lambda=0.15405 \mathrm{~nm}$, as shown in Figure 3. The main diffraction peak was located at $34.58^{\circ}$, which corresponds to the (002) diffraction plane of pure wurtzite $\mathrm{ZnO}$ structure. The pure $\mathrm{ZnO}$ sample displayed a hexagonal wurtzite phase (JCPDS Card No. 36-1451) and no secondary phase. The same diffraction peaks can be also illustrated in the XRD patterns of the NZO NR arrays. The location of the impurity peaks was not found, thereby implying that the investigated pure $\mathrm{ZnO}$ and $\mathrm{NZO}$ samples have good crystalline properties [31]. Meanwhile, it is preferentially oriented along the c-axis, which means that all the samples were oriented perpendicular to the substrate. The red-shift of the diffraction peak was also derived from the decrease in d-spacing; this condition is defined by the following equation (Bragg's Law) [32]:

$$
\mathrm{n} \cdot \lambda=2 \mathrm{~d} \cdot \sin \theta
$$

where $\mathrm{n}$ is the order of diffraction, $\lambda$ is the $\mathrm{X}$-ray wavelength, $\theta$ is the angle of diffraction, and the value of $d$ is the distance between planes. The shifting of the (002) peaks was toward the right side with $\mathrm{Ni}$ doping. This movement shows that a small $\mathrm{Ni}^{2+}$ (ionic radius $=69 \mathrm{pm}$ ) has been effectively incorporated or substituted into the $\mathrm{ZnO}$ host structure at the $\mathrm{Zn}^{2+}$ (ionic radius $=74 \mathrm{pm}$ ) site. These similar results were also observed in a previous report [33].

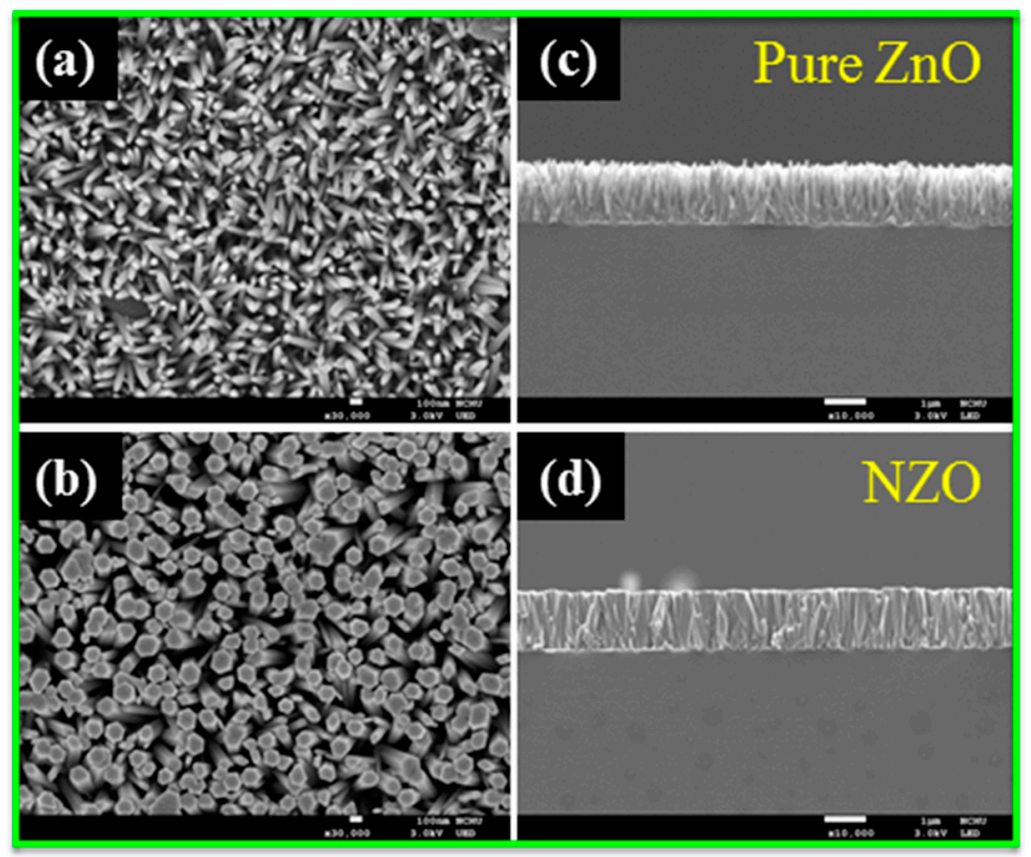

Figure 2. Pure $\mathrm{ZnO}$ and NZO NRs have a well-aligned shape in the vertical direction, as shown in the top-view $(\mathbf{a}, \mathbf{b})$ and cross-section (c,d) field-emission scanning electron microscopy (FE-SEM). 


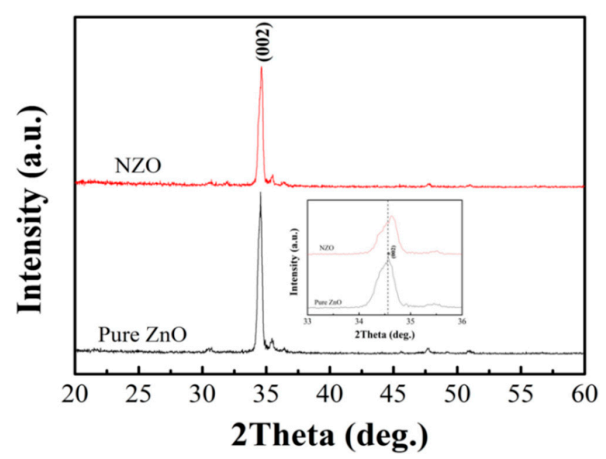

Figure 3. X-ray diffraction (XRD) patterns of pure $\mathrm{ZnO}$ and $\mathrm{NZO}$ NRs (enlarged view of the

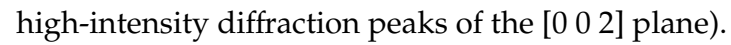

All samples were annealed at $600{ }^{\circ} \mathrm{C}$ in air environment and characterized via PL spectrometer. PL spectroscopy was employed to measure the optical emissions from $300 \mathrm{~nm}$ to $700 \mathrm{~nm}$ with a $325 \mathrm{~nm}$ $\mathrm{He}-\mathrm{Cd}$ laser with $25 \mathrm{~mW}$ increment at room temperature. Figure 4 shows that each sample exhibited two types of emission peak at wavelength of $\sim 380(3.26 \mathrm{eV})$ and $560 \mathrm{~nm}(2.21 \mathrm{eV})$, corresponding to a strong ultraviolet (UV) radiation (near band emission, NBE) and a visible-light emission (deep-level emission, DLE), respectively. The energy of the peak due to UV emission was almost equal to the band gap energy of the $\mathrm{ZnO}$ structure. By contrast, the visible-light emission of $\mathrm{ZnO}$ was yellow-green and depended on the availability of oxygen vacancies. The yellow-green emission region was attributed to the recombination of electrons trapped in singly ionized oxygen vacancies with holes and the inherent defects in the $\mathrm{ZnO}$ structure, such as zinc vacancy, interstitial zinc, oxygen vacancy $\left(\mathrm{V}_{\mathrm{O}}\right)$, and interstitial oxygen [34,35]. After Ni doping, the UV peak showed a slight red-shift from $379 \mathrm{~nm}$ to $383 \mathrm{~nm}$, and the visible emission intensity gradually decreased. The above-mentioned phenomena can be attributed to the following: (1) the localized " $\mathrm{d}$ " electrons of $\mathrm{Ni}^{2+}$ replaced those of $\mathrm{Zn}^{2+}$, (2) the sp-d exchange interactions between the electrons of band, and (3) $V_{O}$ regions were eliminated by annealing treatment at high temperature in air conditions. As a result, it was observed that Ni-doping can improve the optical properties of $\mathrm{ZnO} N R$ arrays; this phenomenon is similar to that reported earlier for NZO structure [36,37].

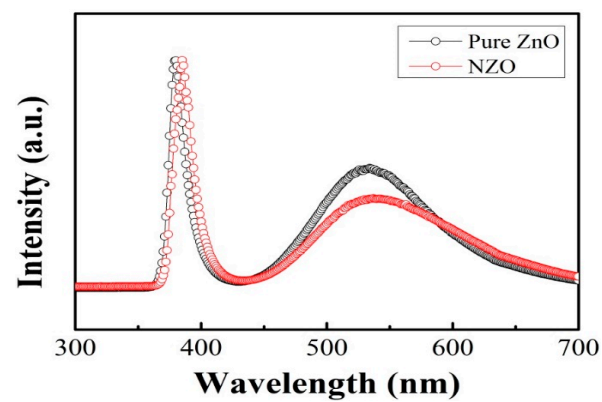

Figure 4. Room-temperature photoluminescence (PL) spectra: comparison of pure $\mathrm{ZnO}$ and $\mathrm{NZO}$ NR arrays.

The nanostructures and lattice spacing relations of NZO sample were explored by transmission electron microscopy (TEM) to further illuminate the detailed structure of the NZO NRs, as shown in Figure 5. In previous work and related literature, NZO NR arrays were obtained in a water solution system through CBD [38]. Figure 5a exhibits the fragments of NZO NR scraped from the sample with ethanol solution and then dropped onto a copper mesh with a dropping pipet. Lastly, the copper mesh was dried at $90^{\circ} \mathrm{C}$ for $2 \mathrm{~h}$ in the oven. Figure $5 \mathrm{~b}, \mathrm{c}$ demonstrate that the HR-TEM image displayed the fringes of NZO planes with an interplanar spacing of approximately $0.259 \mathrm{~nm}$. This manifestation indicates that the NZO NR is a single crystalline structure and can grow along the (002) direction, which is in accordance with selected-area electron diffraction (SAED) pattern shown in the upper right 
of Figure 5b. The figure shows that the NZO structure exhibited a hexagonal wurtzite phase and good crystallinity. Figure 5d-g depict the TEM elemental mapping images for a selected area (inside the pink rectangular frame) of the NZO NR arrays. Ni was uniformly doped into the $\mathrm{ZnO}$ structure with the visualized elemental distribution of $\mathrm{Zn}$ (red), $\mathrm{O}$ (green), and Ni (cyan). The NZO NRs were annealed at $600{ }^{\circ} \mathrm{C}$ and then analyzed via an EDX spectrometer. The presence of $\mathrm{Ni}$ was confirmed. Figure $5 \mathrm{~h}$ exhibits the EDX spectra of the NZO structure. The spectra imply that three elements, namely, Zn, O, and Ni, exist in the NZO NR arrays. No traces of other elements were displayed in the spectra, thereby confirming the purity of the samples and successful doping of $\mathrm{Ni}^{2+}$. The atomic percentages of $\mathrm{Zn}, \mathrm{O}$, and $\mathrm{Ni}$ in the NR arrays were $61.64 \%, 37.87 \%$, and $0.49 \%$, respectively. Based on the above analysis, we can definitely conclude that the NZO NRs were obtained by the simple CBD method. In addition, it illustrates that the synthesis method is reliable for the doping process.

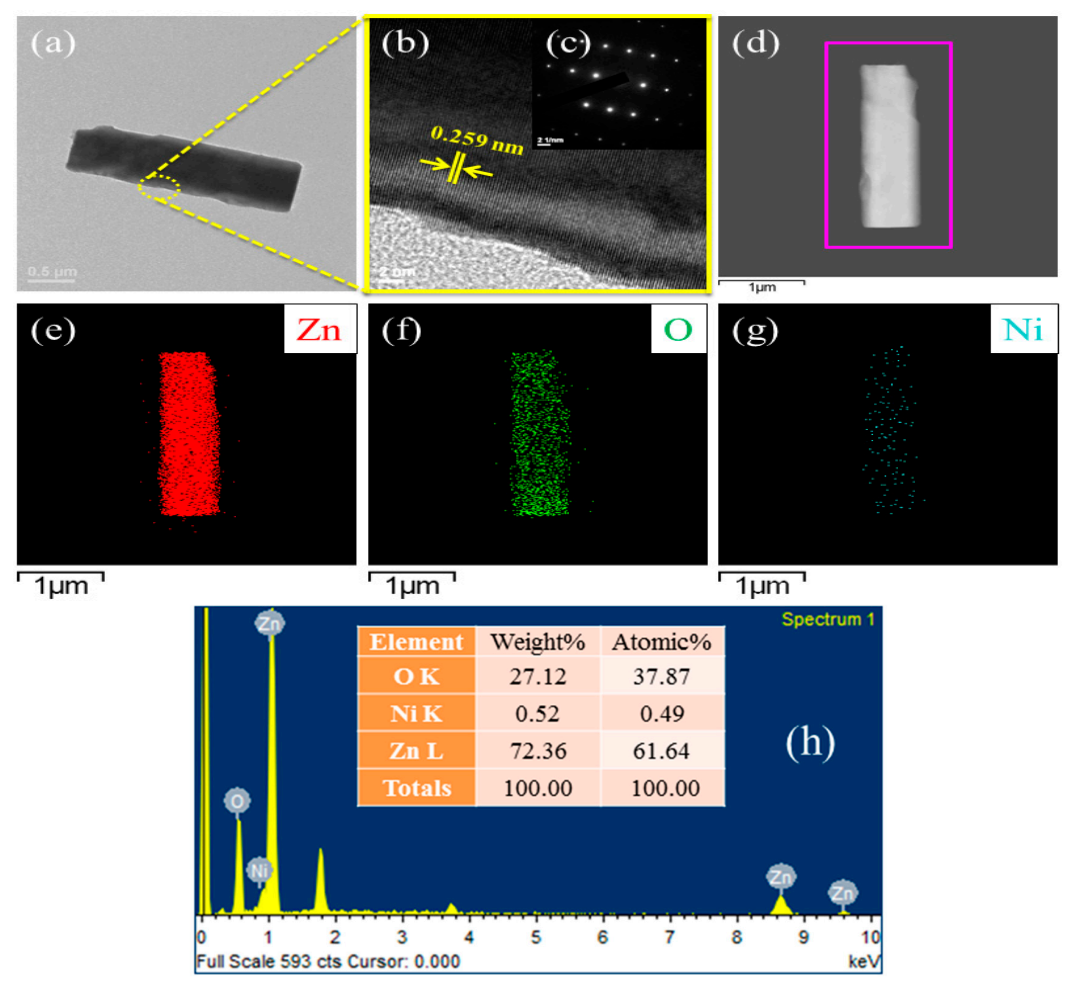

Figure 5. (a) Typical transmission electron microscopy (TEM) image of a single NZO structure; $(\mathbf{b}, \mathbf{c})$ HR-TEM image; the inset is a selected-area electron diffraction (SAED) image, which indicates NZO NR with a single crystal structure; $(\mathbf{d}-\mathbf{g})$ TEM elemental mapping of the selected region showing the existence of $\mathrm{Zn}$ (red), O (green), and Ni (cyan); (h) energy dispersive X-ray (EDX) analysis of highly oriented NZO NRs prepared by chemical bath deposition (CBD).

Figure 6 exhibits the average voltage, current, and power characteristics of the $\mathrm{ZnO}$ NGs fabricated through pure $\mathrm{ZnO}$ and NZO NR arrays grown for $3 \mathrm{~h}$. To characterize the electrical performance of the NGs, the samples were driven by the fluctuation generated with an ultrasonic oscillator machine and a precision digital meter (Keithly 2400). The voltage was from $-3 \mathrm{~V}$ to $+3 \mathrm{~V}$, and it was measured from approximately $1 \mathrm{~min}$ with $\sim 5 \mathrm{~s}$ start and $\sim 5 \mathrm{~s}$ closing. Figure $6 \mathrm{a}, \mathrm{b}$ show the voltage-time $(V-T)$ curves of the $\mathrm{ZnO}$ NRs with and without Ni dopant. The average voltages of pure $\mathrm{ZnO}$ and NZO NRs were 0.006 and $0.07 \mathrm{~V}$, respectively. Figure $6 \mathrm{c}-\mathrm{d}$ present the current-time $(I-T)$ image of the two NG devices. The average currents were 0.0733 and $10.5 \mu \mathrm{A}$. Finally, the output power values were 0.44 and $735 \mathrm{nW}$. The NG device power density $(\mathrm{P})$ is expressed in the following equation [39]:

$$
\mathrm{P}=\mathrm{I} \cdot \mathrm{V} / \mathrm{V}
$$


where $\mathrm{I}$ is the average current, $\mathrm{V}$ is the average voltage, and $\mathrm{v}$ is the volume of NRs. From the viewpoint of the total power, the $\mathrm{ZnO}$ NR arrays with $5 \mathrm{mM}$ Ni content showed excellent performance. Figure $6 \mathrm{e}$ shows the current-voltage $(I-V)$ curve property. The results displayed that the corresponding currents of pure ZnO NRs and NZO NRs were $-0.043 \sim 0.80 \mathrm{~mA}$ and $-1.32 \sim 3.66 \mathrm{~mA}$, respectively. The Schottky contact behavior can be observed between the Au metal and the NR oxide material [37]. The electrical property of NZO NR arrays was stable and demonstrated a nearly symmetrically nonlinear behavior in the Schottky curve compared with pure $\mathrm{ZnO}$. Simultaneously, it can be seen that the measured duration time of NZO samples is more stable than pure $\mathrm{ZnO}$ samples. The above-mentioned results indicate that NZO NGs can produce more output power than pure ZnO NGs. As we know, the length of NRs is too long; the NR structure may break easily while the sample is measured. On the other hand, an appropriate diameter of the NRs can produce a significant bite force between the electrodes. Additionally, some intrinsic defects may also be introduced by increasing the $\mathrm{Ni}$ concentration in $\mathrm{ZnO}$ NR arrays, Hence, the response for output power values of the NZO NGs may be greatly improved by selecting the optimal Ni content in ZnO NRs appropriately. By contrast, $\mathrm{Ni}$ can contribute to the formation of hole carriers, and the conductivity of NZO will be enhanced, thereby resulting in the fast transmission speed of NGs [40-45].
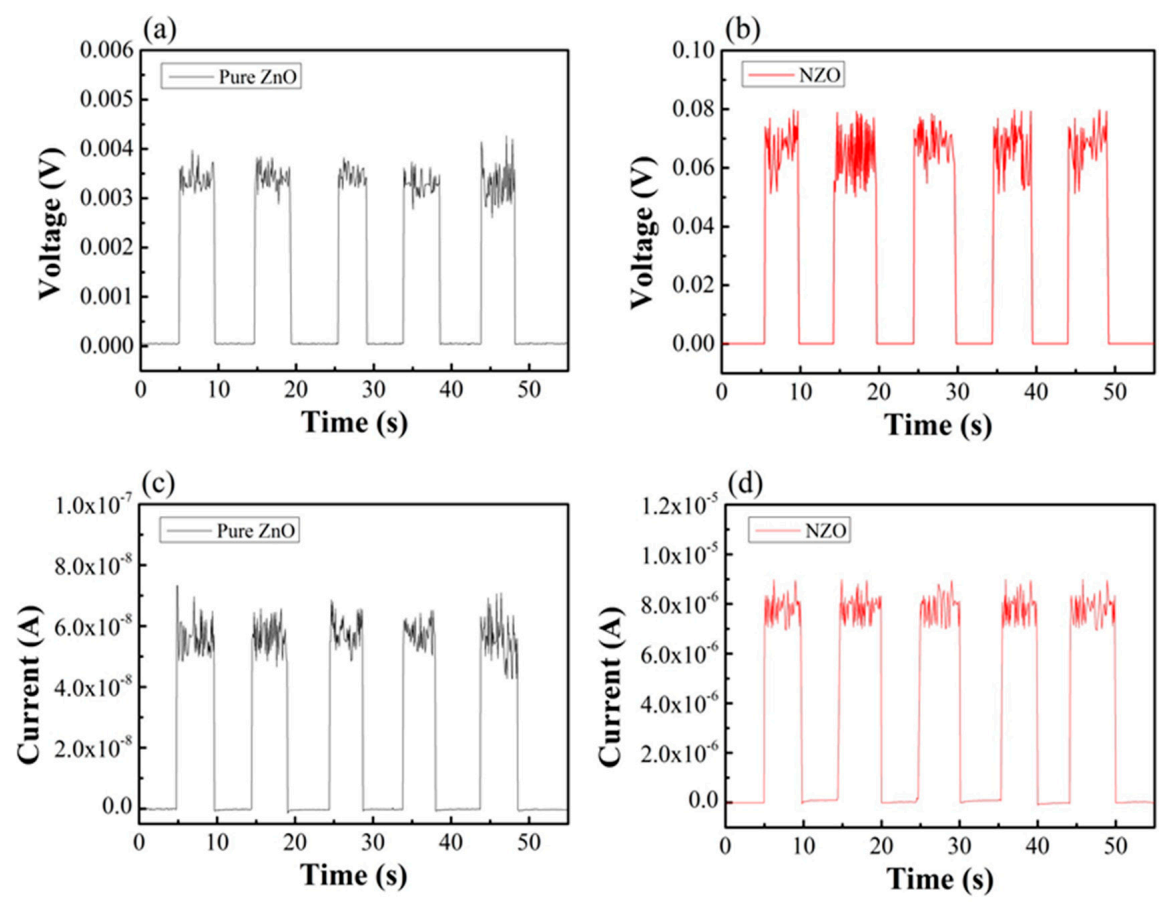

(e)

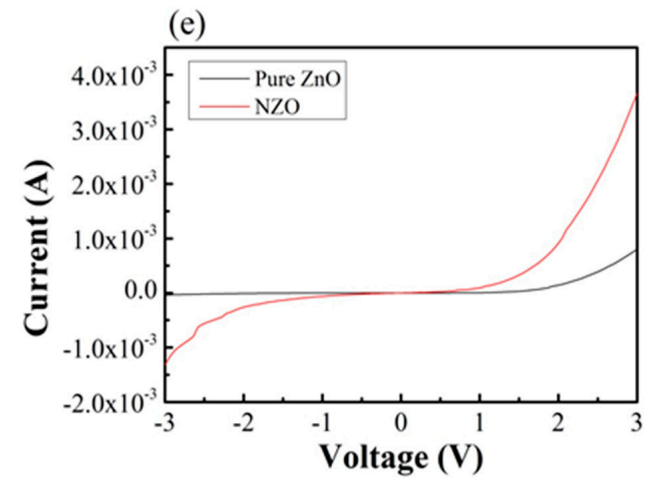

Figure 6. (a-e) Voltage-Time $(V-T)$, Current-Time $(I-T)$, and Current-Voltage $(I-V)$ characteristics of pure $\mathrm{ZnO}$ and NZO NR-based NG devices at applied biases of $-3 \mathrm{~V}$ to $3 \mathrm{~V}$. 


\section{Conclusions}

As previously demonstrated, NGs based on NZO NRs were successfully fabricated and characterized in this investigation. The NZO NR arrays were synthesized by CBD on ITO glass substrates. XRD and TEM analyses confirmed that the NZO NR arrays had a hexagonal wurtzite phase and a single crystalline structure. CBD was used to grow NZO NRs in a $95^{\circ} \mathrm{C}$ oven for $3 \mathrm{~h}$ and the pattern was defined on the ITO glass substrates, and ITO etching paste was used as etchant for etching in an oven at $170{ }^{\circ} \mathrm{C}$ for $5 \mathrm{~min}$. A $100 \mathrm{~nm}$ Au layer was subsequently evaporated onto the surface as an electrode. Finally, the NZO NR arrays and electrodes were combined to form NGs to explore their characteristics. The results show that the synthesis of $\mathrm{ZnO}$ NRs with Ni concentration was predicted to exhibit enhanced performance of NGs compared with pure ZnO. In other words, while the NZO sample is measured, it can produce a large number of hole carriers and easily bend, which can significantly generate high output power values. In the future, the produced NZO nanostructure can also be combined with the Internet of Things for its incorporation into self-powered applications such as implantable biomedical devices, wireless sensors, and portable electronics.

Author Contributions: Y.-L.C. and P.-H.C. performed the experiments; S.-J.Y. and L.-W.J. conceived the experiments; T.-T.C. participated in data analysis. All authors have read and agreed to the published version of the manuscript

Funding: This research received no external funding.

Acknowledgments: This work was financially supported by the Ministry of Science and Technology of Taiwan, with project numbers: MOST 107-2221-E-150-032, MOST 108-2221-E-024-006, MOST 108-2221-E-150-013-MY2, MOST 108-2622-E-150-010-CC3, and MOST 106-2221-E-150-041-MY3. The authors would like to thank the Common Laboratory for Micro/Nano Science and Technology of the National Formosa University for the use of their measurement equipment and their assistance in this work, the Center for Micro/Nano Science and Technology, National Cheng Kung University, for device characterization, and P.H. Chen for device fabrication and equipment support.

Conflicts of Interest: The authors declare no conflict of interest.

\section{References}

1. Katz, E.; Buckmann, A.F.; Willner, I. Self-powered enzyme-based biosensors. J. Am. Chem. Soc. 2001, 123, 10752-10753. [CrossRef] [PubMed]

2. Dondi, D.; Bertacchini, A.; Brunelli, D.; Larcher, L.; Benini, L. Modeling and optimization of a solar energy harvester system for self-powered wireless sensor networks. IEEE Trans. Ind. Electron. 2008, 55, 2759-2766. [CrossRef]

3. Bhatia, D.; Sharma, H.; Meena, R.S.; Palkar, V.R. A novel ZnO piezoelectric microcantilever energy scavenger: Fabrication and characterization. Sens. Biosens. Res. 2016, 9, 45-52. [CrossRef]

4. Hu, Y.F.; Xu, C.; Zhang, Y.; Lin, L.; Snyder, R.L.; Wang, Z.L. A nanogenerator for energy harvesting from a rotating tire and its application as a self-powered pressure/speed sensor. J. Adv. Mater. 2011, 23, 4068-4071. [CrossRef]

5. Hsu, C.L.; Chen, K.C. Improving piezoelectric nanogenerator comprises $\mathrm{ZnO}$ nanowires by bending the flexible PET substrate at low vibration frequency. J. Phys. Chem. C 2012, 116, 9351-9355. [CrossRef]

6. Ko, Y.H.; Nagaraju, G.; Lee, S.H.; Yu, J.S. PDMS-based triboelectric and transparent nanogenerators with ZnO nanorod arrays. ACS Appl. Mater. Interfaces 2014, 6, 6631-6637. [CrossRef]

7. Yang, Y.; Guo, W.X.; Pradel, K.C.; Zhu, G.; Zhou, Y.S.; Zhang, Y.; Hu, Y.F.; Lin, L.; Wang, Z.L. Pyroelectric nanogenerators for harvesting thermoelectric energy. Nano Lett. 2012, 12, 2833-2838. [CrossRef]

8. Wang, X.D.; Gao, Y.F.; Wei, Y.G.; Wang, Z.L. Output of an ultrasonic wave-driven nanogenerator in a confined tube. Nano Res. 2009, 2, 177-182. [CrossRef]

9. Lu, M.P.; Song, J.; Lu, M.Y.; Chen, M.T.; Gao, Y.; Chen, L.J.; Wang, Z.L. Piezoelectric nanogenerator using p-type $\mathrm{ZnO}$ nanowire arrays. Nano Lett. 2009, 9, 1223-1227. [CrossRef]

10. Liu, C.W.; Chang, S.J.; Hsiao, C.H.; Lo, K.Y.; Kao, T.H.; Wang, B.C.; Young, S.J.; Tsai, K.S.; Wu, S.L. Noise properties of low-temperature-grown Co-doped $\mathrm{ZnO}$ nanorods as ultraviolet photodetectors. IEEE J. Sel. Top. Quantum Electron. 2014, 20, 3800707. 
11. Fang, X.S.; Zhai, T.Y.; Gautam, U.K.; Li, L.; Wu, L.M.; Bando, Y.S.; Golberg, D. ZnS nanostructures: From synthesis to applications. Prog. Mater Sci. 2011, 56, 175-287. [CrossRef]

12. Astakhov, G.V.; Yakovlev, D.R.; Kochereshko, V.P.; Ossau, W.; Faschinger, W.; Puls, J.; Henneberger, F.; Crooker, S.A.; McCulloch, Q.; Wolverson, D.; et al. Binding energy of charged excitons in ZnSe-based quantum wells. Phys. Rev. B. 2002, 65, 165335. [CrossRef]

13. Orton, J.W. Acceptor binding energy in GaN and related alloys. Semicond. Sci. Technol. 1995, 10, 101-104. [CrossRef]

14. Young, S.J.; Tang, W.L. Wireless Zinc Oxide Based pH Sensor System. J. Electrochem. Soc. 2019, 166, B3047-B3050. [CrossRef]

15. Chu, Y.L.; Ji, L.W.; Lu, H.Y.; Young, S.J.; Tang, I.T.; Chu, T.T.; Guo, J.S.; Tsai, Y.T. Fabrication and Characterization of UV Photodetectors with Cu-Doped ZnO Nanorod Arrays. J. Electrochem. Soc. 2020, 167, 027522. [CrossRef]

16. Al-Ruqeishi, M.S.; Mohiuddin, T.; Al-Habsi, B.; Al-Ruqeishi, F.; Al-Fahdi, A.; Al-Khusaibi, A. Piezoelectric nanogenerator based on $\mathrm{ZnO}$ nanorods. Arab. J. Chem. 2016, 12, 5173-5179. [CrossRef]

17. Fang, X.; Li, J.H.; Zhao, D.X.; Shen, D.Z.; Li, B.H.; Wang, X.H. Phosphorus-doped p-type ZnO nanorods and $\mathrm{ZnO}$ nanorod p-n homojunction LED fabricated by hydrothermal method. J. Phys. Chem. C 2009, 113, 21208-21212. [CrossRef]

18. Tsai, Y.T.; Chang, S.J.; Ji, L.W.; Hsiao, Y.J.; Tang, I.T.; Lu, H.Y.; Chu, Y.L. High Sensitivity of NO Gas Sensors Based on Novel Ag-Doped ZnO Nanoflowers Enhanced with a UV Light-Emitting Diode. ACS Omega 2018, 3, 13798-13807. [CrossRef]

19. Young, S.J.; Wang, T.H. ZnO Nanorods Adsorbed with Photochemical Ag Nanoparticles for IOT and Field Electron Emission Application. J. Electrochem. Soc. 2018, 165, B3043-B3045. [CrossRef]

20. Bae, S.Y.; Na, C.W.; Kang, J.H.; Park, J. Comparative structure and optical properties of Ga-, In-, and Sn-doped $\mathrm{ZnO}$ nanowires synthesized via thermal evaporation. J. Phys. Chem. B 2005, 109, 2526-2531. [CrossRef]

21. Wu, D.; Yang, M.; Huang, Z.; Yin, G.; Liao, X.; Kang, Y.; Chen, X.; Wang, H. Preparation and properties of Ni-doped $\mathrm{ZnO}$ rod arrays from aqueous solution. J. Colloid Interface Sci. 2009, 330, 380-385. [CrossRef] [PubMed]

22. Chikoidze, E.; Modreanu, M.; Sallet, V.; Gorochov, O.; Galtier, P. Electrical properties of chlorine-doped ZnO thin films grown by MOCVD. Phys. Status Solidi A 2008, 205, 1575-1579. [CrossRef]

23. Liu, Y.H.; Young, S.J.; Ji, L.W.; Chang, S.J. Noise Properties of Mg-Doped ZnO Nanorods Visible-Blind Photosensors. IEEE J. Sel. Top. Quantum Electron. 2015, 21, 3800405. [CrossRef]

24. Wang, Z.L.; Song, J.H. Piezoelectric nanogenerators based on zinc oxide nanowire arrays. Science 2006, 312, 242-246. [CrossRef]

25. Wang, X.; Song, J.; Liu, J.; Wang, Z.L. Direct-current nanogenerator driven by ultrasonic waves. Science 2007, 316, 102-105. [CrossRef]

26. Elkamel, I.B.; Hamdaoui, N.; Mezni, A.; Ajjel, R.; Beji, L. High responsivity and 1/f noise of an ultraviolet photodetector based on Ni doped ZnO nanoparticles. RSC Adv. 2018, 8, 32333-32343. [CrossRef]

27. Chiu, S.H.; Huang, J.C.A. Chemical bath deposition of $\mathrm{ZnO}$ and $\mathrm{Ni}$ doped $\mathrm{ZnO}$ nanorod. J. Non-Cryst. Solids 2012, 358, 2453-2457. [CrossRef]

28. Chen, C.C.; Wu, T.L.; Meen, T.H.; Chen, C.Y.; Su, C.H.; Tsai, J.K.; Lee, C.Y.; Lee, C.H.; Liu, D.S. ZnO Nanogenerator Prepared from ZnO Nanorods Grown by Hydrothermal Method. Sens. Mater. 2019, 31, 1083-1089. [CrossRef]

29. Kim, K.H.; Jin, Z.; Abe, Y.; Kawamura, M. A comparative study on the structural properties of ZnO and Ni-doped ZnO nanostructures. Mater. Lett. 2015, 149, 8-11. [CrossRef]

30. Dong, X.; Wang, J.; Wang, H.; Shi, Z.F.; Zhang, B.L. Adjust the Content of Nickel in NiZnO Films by Vacuum Anneal. Adv. Mater. Res. 2012, 562, 11-14. [CrossRef]

31. Chithira, P.R.; John, T.T. Defect and dopant induced room temperature ferromagnetism in Ni doped ZnO nanoparticles. J. Alloy. Compd. 2018, 766, 572-583. [CrossRef]

32. Chand, P.; Gaur, A.; Kumar, A.; Gaur, U.K. Structural, morphological and optical study of Li doped ZnO thin films on Si (100) substrate deposited by pulsed laser deposition. Ceram. Int. 2014, 40, 11915-11923. [CrossRef]

33. Shannon, R.D. Revised effective ionic radii and systematic studies of interatomic distances in halides and chalcogenides. Acta. Cryst. 1976, A32, 751-767. [CrossRef] 
34. Dinesha, M.L.; Jayanna, H.S.; Mohanty, S.; Ravi, S. Structural, electrical and magnetic properties of Co and Fe co-doped ZnO nanoparticles prepared by solution combustion method. J. Alloy. Compd. 2010, 490, 618-623. [CrossRef]

35. Yang, P.; Yan, H.; Mao, S.; Russo, R.; Johnson, J.; Saykally, R.; Morris, N.; Phan, J.; He, R.; Choi, H.J. Controlled Growth of ZnO Nanowires and Their Optical Properties. Adv. Funct. Mater. 2002, 12, 323-331. [CrossRef]

36. Modaberi, M.R.; Rooydell, R.; Brahma, S.; Akande, A.A.; Mwakikunga, B.W.; Liu, C.P. Enhanced response and selectivity of $\mathrm{H}_{2} \mathrm{~S}$ sensing through controlled Ni doping into $\mathrm{ZnO}$ nanorods by using single metal organic precursors. Sens. Actuators B Chem. 2018, 273, 1278-1290. [CrossRef]

37. He, J.H.; Lao, C.S.; Chen, L.J.; Davidovic, D.; Wang, Z.L. Large-Scale Ni-Doped ZnO Nanowire Arrays and Electrical and Optical Properties. J. Am. Chem. Soc. 2005, 127, 16376-16377. [CrossRef]

38. Chu, Y.L.; Ji, L.W.; Hsiao, Y.J.; Lu, H.Y.; Young, S.J.; Tang, I.T.; Chu, T.T.; Chen, X.J. Fabrication and Characterization of Ni-Doped ZnO Nanorod Arrays for UV Photodetector Application. J. Electrochem. Soc. 2020, 167, 067506. [CrossRef]

39. Hu, C.J.; Lin, Y.H.; Tang, C.W.; Tsai, M.Y.; Hsu, W.K.; Kuo, H.F. ZnO-coated carbon nanotubes: Flexible piezoelectric generators. Adv. Mater. 2011, 23, 2941-2945. [CrossRef]

40. Wang, Z.L. Zinc oxide nanostructures: Growth, properties and applications. J. Phys. Condens. Mater. 2004, 16, R829-R858. [CrossRef]

41. Kind, H.; Yan, H.Q.; Messer, B.; Law, M.; Yang, P.D. Nanowire Ultraviolet Photodetectors and Optical Switches. Adv. Mater. 2002, 14, 158-160. [CrossRef]

42. Rajalakshmi, R.; Angappane, S. Synthesis, characterization and photoresponse study of un-doped and transition metal (Co, Ni, Mn) doped ZnO thin films. Mater. Sci. Eng. B 2013, 178, 1068-1075.

43. Islam, R.; Chen, G.; Ramesh, P.; Suh, J.; Fuchigami, N.; Lee, D.; Littau, K.A.; Weiner, K.; Collins, R.T.; Saraswat, K.C. Investigation of the Changes in Electronic Properties of Nickel Oxide (NiOx) Due to UV/Ozone Treatment. ACS Appl. Mater. Interfaces 2017, 9, 17201-17207. [CrossRef] [PubMed]

44. Iqbal, J.; Wang, B.Q.; Liu, X.F.; Yu, D.P.; He, B.; Yu, R.H. Oxygen-vacancy-induced green emission and room-temperature ferromagnetism in Ni-doped ZnO nanorods. New J. Phys. 2009, 11, 063009. [CrossRef]

45. Hu, Y.F.; Zhang, Y.; Xu, C.; Zhu, G.A.; Wang, Z.L. High-Output Nanogenerator by Rational Unipolar Assembly of Conical Nanowires and Its Application for Driving a Small Liquid Crystal Display. Nano Lett. 2010, 10, 5025-5031. [CrossRef] 